\title{
Decreased expression of LMO7 and its clinicopathological significance in human lung adenocarcinoma
}

\author{
HIROYUKI NAKAMURA ${ }^{1}$, KEIKO HORI $^{2}$, MIKI TANAKA-OKAMOTO ${ }^{2}$, MASAHIKO HIGASHIYAMA $^{3}$, \\ YU ITOH $^{2}$, MASAHIRO INOUE ${ }^{1}$, SETSUKO MORINAKA $^{4}$ and JUN MIYOSHI ${ }^{2}$ \\ Departments of ${ }^{1}$ Biochemistry, ${ }^{2}$ Molecular Biology, and ${ }^{3}$ Thoracic Surgery, Osaka Medical Center for Cancer \\ and Cardiovascular Diseases, Osaka 537-8511; ${ }^{4}$ Department of Otorhinolaryngology, \\ Kobe Japanpost Hospital, Kobe 651-8798, Japan
}

Received July 9, 2011; Accepted August 8, 2011

DOI: $10.3892 /$ etm.2011.329

\begin{abstract}
LIM-domain only protein 7 (LMO7) has been suggested to act as a tumor suppressor for murine lung adenocarcinoma, while its splice variant p100 LMO7/\#16 is associated with invasion and metastasis of rat AH130W1 cells. However, the importance of LMO7 in human lung cancer is unknown. We investigated LMO7 protein expression by immunohistochemistry in tumor tissues obtained from 57 patients with adenocarcinoma of the lung using a rabbit anti-LMO7 antibody. Signals for LMO7 were localized to the apical surface of the bronchial epithelium and to the cell membranes of pneumocytes in non-cancerous pulmonary tissues, but were noted circumferentially around the plasma membrane of cancer cells in all 57 patients with adenocarcinoma. The LMO7-positive group (24 patients, $42 \%$ ) showed equivocal to strong expression of LMO7 in more than $50 \%$ cancer cells, while the remaining 33 patients (58\%) showed LMO7 expression in less than $50 \%$ of their cancer cells. The latter group had significantly more advanced disease than the LMO7-positive group with regard to $\mathrm{T}$ factor $(\mathrm{p}=0.011)$, nodal involvement $(\mathrm{p}=0.026)$ and $\mathrm{p}$-stage $\left(\mathrm{p}=0.010 ; \chi^{2}\right.$ test $)$. Multivariate analysis using a logistic regression model showed that LMO7 expression was independently associated with the $\mathrm{T}$ factor $(\mathrm{p}=0.041)$. Kaplan-Meier analysis showed that a poor prognosis was associated with low expression of LMO7 ( $p=0.036$; log-rank test). Our findings are consistent with earlier observations and demonstrate that LMO7 is inversely correlated with the development and prognosis of human lung adenocarcinoma.
\end{abstract}

Correspondence to: Dr Hiroyuki Nakamura, Department of Biochemistry, Osaka Medical Center for Cancer and Cardiovascular Diseases, 1-3-3 Nakamichi, Higashinari-ku, Osaka 537-8511, Japan E-mail: s-morinaka@kobe-japanposthospital.jp

Abbreviations: LMO7, LIM-domain only protein 7; PCD1, pancreatic cancer derived 1 ; TGF- $\beta$, transforming growth factor- $\beta$; GST, glutathione S-transferase

Key words: LIM-domain only protein 7, immunohistochemistry, human lung adenocarcinoma

\section{Introduction}

Lung cancer is the leading cause of cancer-related death in the world (1). Despite various advances in anticancer therapy, survival rates have not improved during the last decade, and long-term survival remains very poor (2-4). Local relapse may occur after surgical removal of the primary tumor, and distant metastasis is not unusual, arising from micrometastases that are undetectable when the primary tumor is diagnosed. Thus, exploring factors that are useful for predicting the progression and outcome of lung cancer is critical.

LIM-domain only protein 7 (LMO7) is a fibrous actin-binding protein that is widely expressed in adult tissues, particularly at the apical surface of lung epithelial cells (5). LMO7 is a member of a family of nine proteins containing both PDZ and LIM domains that function as protein-protein recognition modules $(6,7)$. The PDZ and LIM families are involved in forming the Z-band of muscles through PDZ domains that bind to $\alpha$-actinin or $\beta$-tropomyosin (8). LMO7 is also involved in the process of gene expression by acting as a nucleocytoplasmic shuttle protein that regulates the transcription of emerin and muscle-related genes (9). Moreover, a yeast two-hybrid study demonstrated that LMO7 binds afadin, the adaptor protein of nectins, at adherens junctions through the LIM domain (8). These observations suggest a role for LMO7 in the formation and maintenance of epithelial architecture via remodeling of the actin cytoskeleton.

On the other hand, a role of LMO7 in cancer pathology has been well documented. The P100 LMO7 splice variant (with a truncated C-terminal region) was originally identified by subtraction and differential hybridization in Yoshida hepatoma AH130W1 cells treated with transforming growth factor- $\beta$ (TGF- $\beta$ ) (10). TGF- $\beta$ induced alternative splicing of the LMO7 gene, as well as promoted the migration of AH130W1 cells in an in vitro invasion assay $(11,12)$. In addition, increased expression of LMO7 (also known as pancreatic cancer derived 1; PCD1) has been reported in cancer of the colorectal region, breast, liver, lung, pancreas, stomach and prostate, suggesting that PCD1 may play a role in cytoskeletal reorganization during carcinogenesis (13-15). Furthermore, the LMO7 gene is located on chromosome $13 \mathrm{q} 22$, which is implicated in hereditary breast cancer $(16,17)$, although it remains controversial whether LMO7 is the only gene responsible (16-18). Finally, LMO7-deficient 
mice develop irregular and protruding epithelial lesions in the terminal and respiratory bronchioles at a young age, and these mice tend to develop lung adenocarcinoma at an older age, suggesting that LMO7 acts as a tumor-suppressor gene and that its deficiency confers a genetic predisposition to lung cancer (5). Despite these findings, the role of LMO7 in human lung carcinogenesis has yet to be studied.

We investigated the level of LMO7 protein expression and its pattern of expression by immunohistochemistry in surgically resected tissues obtained from 57 patients with primary lung adenocarcinoma. We also analyzed how LMO7 expression in tumor tissues influenced the progression of cancer and the prognosis of these patients.

\section{Materials and methods}

Surgical specimens. A total of 57 formalin-fixed samples of primary lung adenocarcinoma and adjacent normal lung tissues were obtained along with clinicopathological data from patients who underwent surgery at the Osaka Medical Center for Cancer and Cardiovascular Diseases (Osaka, Japan) between April 2000 and July 2002. All patients underwent potentially curative surgery without perioperative adjuvant therapy. Further treatment was administered only when the cancer recurred. The patients consisted of 31 men and 26 women, 42-79 years of age (mean 61.9).

Histologic classification of the tumor specimens was based on the WHO criteria. Eight patients had tumors with an acinar growth pattern, 42 had a papillary tumor pattern, 2 had bronchioloalveolar tumors and 5 had solid tumors with mucin formation (19). All tumors were staged according to the pTNM pathological classification of the International Union Against Cancer (20). There were 11 patients with p-stage IA, 18 with p-stage IB, 1 with p-stage IIA, 9 with p-stage IIB, 10 with p-stage IIIA and 8 with p-stage IIIB disease. The median postoperative follow-up period was 73 months (range 3-115).

Immunohistochemistry. To investigate LMO7 protein expression, thin sections were cut from $10 \%$ formalin-fixed and paraffin-embedded blocks of the surgical specimens, and were stained with a rabbit anti-LMO7 antibody (clone \#863) as previously described (5). This antibody was specific for a recombinant protein containing amino acid residues of rat p100 \#16/LMO7 (GeneBank accession no. AY609384), which was constructed as a fusion protein with glutathione $\mathrm{S}$ transferase (GST) using the pGEX plasmid vector (GE Healthcare UK Ltd., Buckinghamshire, UK) and was then employed as an immunogen.

Sections $(4 \mu \mathrm{m})$ of tissues were mounted on poly-Llysine-coated slides, air-dried and deparaffinized. Then, endogenous peroxidase activity was blocked by incubation with $5 \%$ hydrogen peroxide in $50 \%$ methanol for $20 \mathrm{~min}$ at room temperature. Subsequently, antigen retrieval was performed by autoclaving at $120^{\circ} \mathrm{C}$ for $3 \mathrm{~min}$ in $10 \mathrm{mM}$ citrate buffer. After blocking non-specific binding by incubation with 5\% skim milk in PBS for $60 \mathrm{~min}$ at room temperature, the sections were incubated with polyclonal anti-LMO7 antibody overnight at $4^{\circ} \mathrm{C}$. After rinsing with PBS, the sections were incubated with biotinylated horse anti-rabbit $\operatorname{IgG}$ (Vector, Burlingame, CA, USA) for $30 \mathrm{~min}$ at room tempera- ture, followed by washing with PBS. Immunoreactivity was detected with an avidin-biotin system (NovaRED ${ }^{\mathrm{TM}}$; Vector). In every control, sections were incubated with a 5-fold excess of GST-LMO7 fusion protein. Adjacent non-cancerous pulmonary tissues were also examined as an internal positive control for LMO7 protein expression.

Classification of immunohistochemical findings. LMO7 expression was primarily detected in the membranes of noncancerous cells, such as pneumocytes, and some bronchial epithelial cells, as well as in cancer cells. Certain cancer cells also showed strong cytoplasmic immunostaining for LMO7. Immunopositivity for LMO7 expression was classified on the basis of the staining intensity. That is, cells with stronger immunostaining were judged to be LMO7-positive, whereas cells with weak or no immunostaining were classed as LMO7-negative.

When the percentage of LMO7-positive cancer cells in a tumor specimen was $\geq 50 \%$, the tumor was classified as LMO7 'positive', while tumors with $<50 \%$ positive cells were characterized as having low LMO7 expression. These semiquantitative assessments were carried out by two independent investigators (H.N. and K.H.) without knowledge of the clinicopathological data.

Statistical analysis. Associations between LMO7 immunostaining and clinicopathological factors were assessed by the $\chi^{2}$ test, except age which was assessed by the Student's t-test. Univariate and multivariate analyses of the clinicopathological factors associated with LMO7 expression were performed by the logistic regression method. Survival curves were calculated from the date of surgery to the time of death (or to final follow-up) according to the Kaplan-Meier method (21), and differences in survival among subgroups were analyzed by the log-rank test (22). Univariate and multivariate analyses of the influence of variables on overall survival were performed with the Cox proportional hazards regression model. Statistical analyses were carried out with SAS software (Cary, NC, USA), and $\mathrm{p}<0.05$ was considered significant.

The surgical samples were obtained from patients after providing informed consent. This study and the use of clinical materials were approved by the relevant institutional research ethics committees. For protection of privacy, identifying information was removed from all samples before analysis in accordance with the Ethical Guidelines for Human Genome/ Gene Research of the Japanese Government.

\section{Results}

Immunohistochemistry for LMO7. We investigated the level and pattern of LMO7 protein positivity by immunohistochemistry of human lung adenocarcinoma specimens because of our previous findings regarding the expression and deficiency of LMO7 in mice (5). Normal bronchioalveolar epithelial cells showed uniformly intense LMO7 positivity. LMO7 was usually localized to the apical membranes of cells from the bronchial epithelium (Fig. 1A), while normal alveolar cells showed circumferential staining of the entire cell membrane (Fig. 1B). The antibody was confirmed to be specific for LMO7 protein because of the complete lack of immunostaining in the adjacent sections after pre-incubation with a 5-fold excess of 

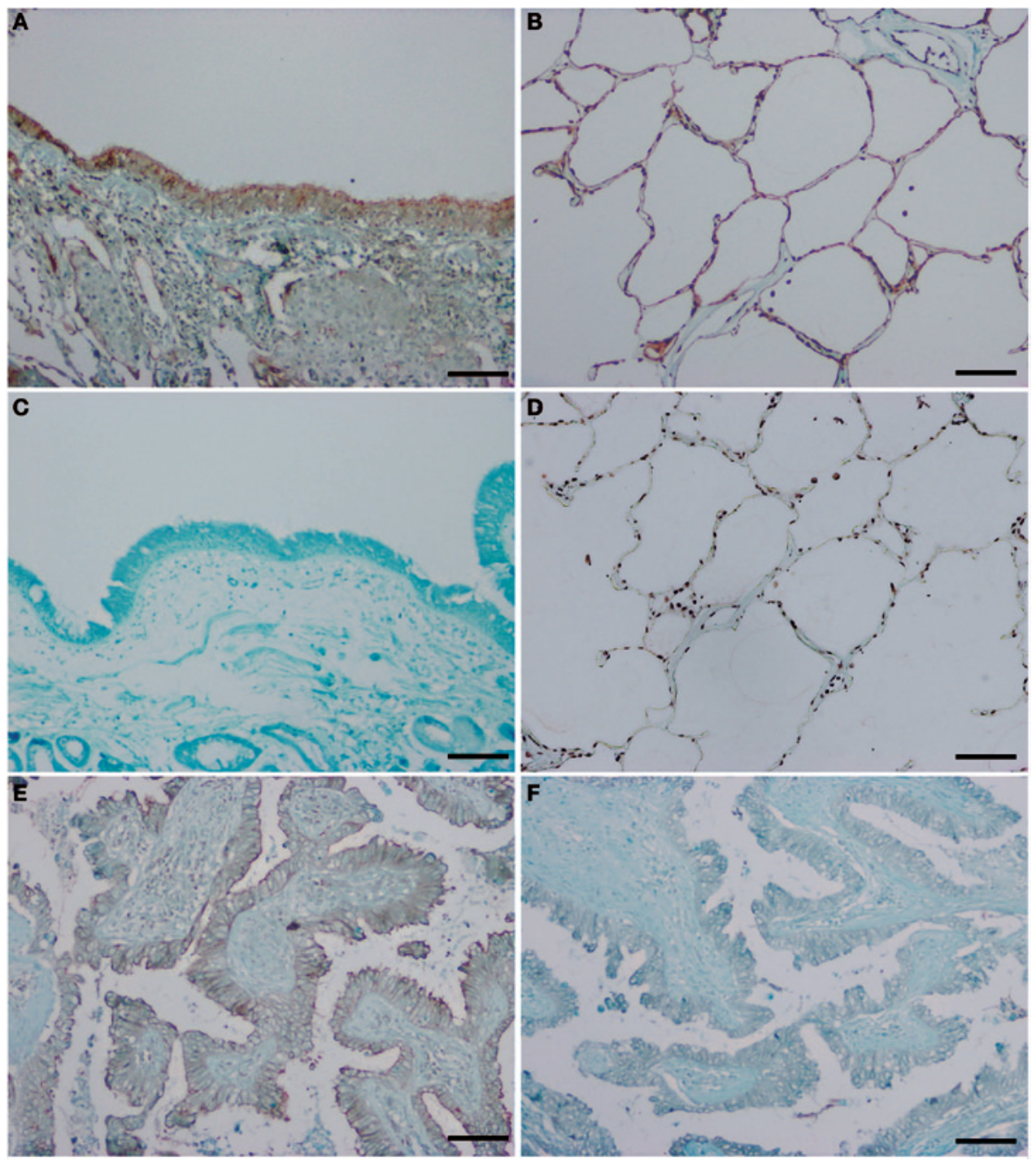

Figure 1. Immunohistochemical expression of LMO7 in primary lung adenocarcinomas and adjacent non-cancerous lung tissues. (A) Intense apical staining localized to the luminal surface of normal bronchiolar epithelial cells. The scale bar represents $50 \mu \mathrm{m}$. (B) Circumferential staining of the entire membrane of normal alveolar cells. The scale bar represents $100 \mu \mathrm{m}$. (C and D) LMO7 immunoreactivity noted in A and B was abolished after pre-incubation with the GST-LMO7 fusion protein, confirming the specificity of the anti-LMO7 antibody. The scale bars represent (C) $50 \mu \mathrm{m}$ and (D) $100 \mu \mathrm{m}$. (E) Circumferential staining of the entire membrane of adenocarcinoma cells. Example of LMO7 positivity. The scale bar represents $100 \mu \mathrm{m}$. (F) LMO7 immunoreactivity noted in E was abolished after pre-incubation with the GST-LMO7 fusion protein. The scale bar represents $100 \mu \mathrm{m}$.

GST-LMO7 fusion protein (Fig. 1C and D). Certain stromal cells, including the smooth muscle cells of blood vessels and vascular endothelial cells, were also stained.

On the other hand, the adenocarcinoma cells of all 57 patients in this study showed circumferential LMO7 staining of the plasma membrane (Fig. 1E). Several patients also had tumor cells with LMO7 expression in the cytoplasm or in part of the apical region. Immunostaining for LMO7 was also abolished by pre-incubation with a 5-fold excess of GST-LMO7 fusion protein (Fig. 1F).

Correlation of decreased LMO7 expression with a poor clinicopathological outcome. To investigate the biological and clinicopathological significance of LMO7, we evaluated the relative intensity of LMO7 staining of the tumor specimens, and classified 33 patients (58\%) and 24 patients (42\%) into a low LMO7 group and an LMO7-positive group, respectively, as described in Materials and methods. The relationship between LMO7 expres- sion and various clinicopathological factors is summarized in Table I. Patients in the low LMO7 group had significantly more advanced tumors than those in the LMO7-positive group with regard to $\mathrm{T}$ factor $(\mathrm{p}=0.011)$, nodal involvement $(\mathrm{p}=0.026)$ and $\mathrm{p}$-stage $(\mathrm{p}=0.010)$. There was no significant relation between LMO7 expression and tumor histology ( $\mathrm{p}=0.9580 ; \chi^{2}$ test).

Logistic regression analysis was performed with the outcome variable being the LMO7 level ('positive' vs. 'low') and the covariates being various clinicopathological factors. On univariate analysis, the $\mathrm{T}$ factor and nodal involvement were positively associated with the level of LMO7 expression. According to multivariate analysis, LMO7 expression was independently associated with the $\mathrm{T}$ factor at the time of surgery ( $\mathrm{p}=0.041)$ (Table II). The results revealed that T1 status was linked to the LMO7-positive group, while T2-4 status was associated with lower expression of LMO7.

When postoperative overall survival curves were drawn according to the level of LMO7 expression in the 57 patients 
Table I. Association between LMO7 expression and clinicopathological factors.

\begin{tabular}{|c|c|c|c|}
\hline & \multicolumn{2}{|c|}{ LMO7 expression ${ }^{\mathrm{a}}$} & \multirow[t]{2}{*}{ p-value } \\
\hline & $\begin{array}{l}\text { Positive } \\
(n=24)\end{array}$ & $\begin{array}{c}\text { Low } \\
(n=33)\end{array}$ & \\
\hline Age (mean $\pm S D ;$ years $)$ & $62.2 \pm 10.2$ & $61.7 \pm 11.3$ & NS \\
\hline \multicolumn{4}{|l|}{ Gender } \\
\hline Male & 13 & 18 & \\
\hline Female & 11 & 15 & 0.977 \\
\hline \multicolumn{4}{|l|}{$\mathrm{T}$ factor } \\
\hline $\mathrm{T} 1$ & 11 & 5 & \\
\hline $\mathrm{T} 2$ & 11 & 19 & \\
\hline $\mathrm{T} 3$ and $\mathrm{T} 4$ & 2 & 9 & $\begin{array}{c}0.011^{\mathrm{c}} \\
(\mathrm{T} 1 \mathrm{vs} . \\
\mathrm{T} 2-4)\end{array}$ \\
\hline \multicolumn{4}{|l|}{ Nodal involvement } \\
\hline NO & 18 & 15 & \\
\hline $\mathrm{N} 1$ & 4 & 5 & \\
\hline $\mathrm{N} 2$ and $\mathrm{N} 3$ & 2 & 13 & $\begin{array}{c}0.026^{\mathrm{b}} \\
\text { (N0 vs. } \\
\text { N1-3) }\end{array}$ \\
\hline \multicolumn{4}{|l|}{ Histological differentiation } \\
\hline Well, moderate & 21 & 27 & \\
\hline Poor & 3 & 6 & 0.561 \\
\hline \multicolumn{4}{|l|}{ p-stage } \\
\hline IA and IB & 17 & 12 & \\
\hline IIA and IIB & 4 & 6 & \\
\hline IIIA and IIIB & 3 & 15 & $\begin{array}{l}0.010^{\mathrm{c}} \\
\text { (I vs. II } \\
\text { and III) }\end{array}$ \\
\hline
\end{tabular}

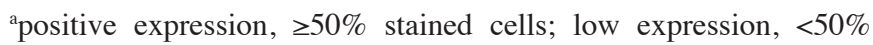
stained cells. ${ }^{\mathrm{b}} \mathrm{p}<0.05 ;{ }^{\mathrm{c}} \mathrm{p}<0.02$. NS, not significant.

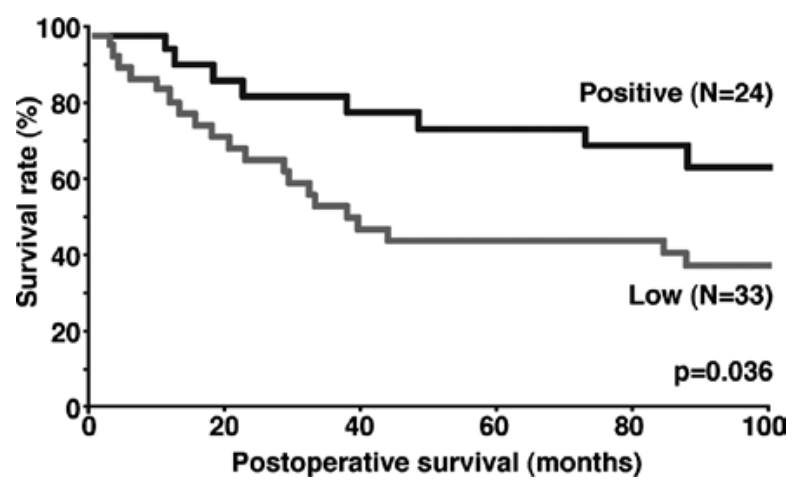

Figure 2. Comparison of Kaplan-Meier survival curves between the low LMO7 expression group and LMO7-positive group of patients with lung adenocarcinoma. The difference of survival between the two groups was statistically significant $(\mathrm{p}=0.036$; log-rank test).

with lung adenocarcinoma, patients in the low expression group had a significantly worse prognosis than those in the LMO7-positive group ( $\mathrm{p}=0.036$ ) (Fig. 2).
Table II. Univariate and multivariate analyses of prognostic indicators with the Cox proportional hazards model.

\begin{tabular}{lcc}
\hline Variables & Risk ratio (95\% CI) & p-value \\
\hline $\begin{array}{l}\text { Univariate model } \\
\text { T factor } \\
\text { (T1 vs.T2-4) }\end{array}$ & $2.893(1.116-9.855)$ & $0.027^{\mathrm{a}}$ \\
$\begin{array}{l}\text { Nodal involvement } \\
\text { (N0 vs. N1-3) }\end{array}$ & $2.276(1.092-4.896)$ & $0.028^{\mathrm{a}}$ \\
$\begin{array}{l}\text { Histological differentiation } \\
\text { (well, moderate vs. poor) }\end{array}$ & $3.226(1.255-7.358)$ & $0.017^{\mathrm{b}}$ \\
$\begin{array}{l}\text { LMO7 expression } \\
\text { (positive vs. low) }\end{array}$ & $2.348(1.071-5.676)$ & $0.033^{\mathrm{a}}$ \\
$\begin{array}{l}\text { Multivariate model } \\
\text { T factor }\end{array}$ & & \\
(T1 vs. T2-4) & $2.996(1.085-10.642)$ & $0.033^{\mathrm{a}}$ \\
$\begin{array}{l}\text { Nodal involvement } \\
\text { (N0 vs. N1-3) }\end{array}$ & $1.509(0.698-3.344)$ & 0.296 \\
$\begin{array}{l}\text { Histological differentiation } \\
\text { (well, moderate vs. poor) }\end{array}$ & $3.889(1.424-9.612)$ & $0.010^{\mathrm{b}}$ \\
$\begin{array}{l}\text { LMO7 expression } \\
\text { (positive vs. low) }\end{array}$ & $1.853(0.813-4.629)$ & 0.146 \\
\hline
\end{tabular}

${ }^{\mathrm{a}} \mathrm{p}<0.05 ;{ }^{\mathrm{b}} \mathrm{p}<0.02$.

Table III. Results of univariate and multivariate logistic regression analyses.

\begin{tabular}{lll}
\hline Model & Odds ratio (95\% CI) & p-value \\
\hline $\begin{array}{l}\text { Univariate model } \\
\text { Age }\end{array}$ & $1.004(0.956-1.056)$ & 0.867 \\
$\begin{array}{l}\text { Gender } \\
\text { (male vs. female) }\end{array}$ & $0.985(0.341-2.856)$ & 0.977 \\
$\begin{array}{l}\text { T factor } \\
\text { (T1 vs. T2-4) }\end{array}$ & $0.211(0.056-0.703)$ & $0.011^{\mathrm{b}}$ \\
$\begin{array}{l}\text { Nodal involvement } \\
\text { (N0 vs. N1-3) }\end{array}$ & $0.278(0.083-0.845)$ & $0.024^{\mathrm{a}}$ \\
$\begin{array}{l}\text { Histological differentiation } \\
\text { (well, moderate vs. poor) }\end{array}$ & $0.643(0.124-2.744)$ & 0.557 \\
$\begin{array}{l}\text { Multivariate model } \\
\text { T factor }\end{array}$ & $0.262(0.065-0.946)$ & $0.041^{\mathrm{a}}$ \\
$\begin{array}{l}\text { (T1 vs. T2-4) } \\
\text { Nodal involvement } \\
\text { (N0 vs. N1-3) }\end{array}$ & $0.391(0.107-1.333)$ & 0.134 \\
$\begin{array}{l}\text { Histological differentiation } \\
\text { (well, moderate vs. poor) }\end{array}$ & $0.734(0.121-3.749)$ & 0.714 \\
\hline
\end{tabular}

${ }^{\mathrm{a}} \mathrm{p}<0.05 ;{ }^{\mathrm{b}} \mathrm{p}<0.02$.

When the Cox proportional hazards model was employed for multivariate analysis, it showed that LMO7 expression was not an independent prognostic factor, although LMO7 
was significantly associated with the prognosis according to univariate analysis (Table II). However, the T factor that was independently associated with LMO7 expression according to logistic regression analysis (Table III) was an independent prognostic indicator in the Cox proportional hazards model (Table II).

\section{Discussion}

To clarify the role of LMO7 in the pathogenesis of human lung adenocarcinoma, we examined LMO7 protein expression with an anti-LMO7 antibody that effectively detects LMO7 under a variety of experimental conditions (5). Our immunohistochemical analysis showed that LMO7 was localized circumferentially in the plasma membrane of adenocarcinoma cells, and that decreased expression of LMO7 was significantly correlated with tumor progression and a poor prognosis of patients with lung adenocarcinoma. LMO7 is mainly expressed by normal bronchiolar and alveolar epithelial cells in the lungs of humans as well as in mice, and a knockout study indicated that LMO7 acts as a tumor suppressor for murine lung adenocarcinoma (5). Therefore, our findings are not only consistent with earlier observations, but also demonstrate that down-regulation of LMO7 expression is related to the clinicopathological features of lung adenocarcinoma and to the prognosis. Of course, this study did not exclude the possibility that down-regulation of LMO7 expression could also be a useful prognostic indicator for other types of cancers, particularly hereditary human breast cancer (16-18).

The low LMO7 expression group was significantly associated with more advanced tumors in the present study. Multivariate logistic regression analysis showed that LMO7 expression was independently associated with the $\mathrm{T}$ factor. Furthermore, Kaplan-Meier analysis of survival revealed a significant difference between the LMO7-positive group and the low expression group in the patients with lung adenocarcinoma. These results support a potential influence of LMO7 on tumor progression and the prognosis of human lung carcinoma. Although Cox proportional hazards analysis failed to identify LMO7 expression as an independent prognostic indicator, the $\mathrm{T}$ factor was an independent variable.

Immunohistochemistry does not provide us with data on the molecular mechanisms underlying changes in protein levels. It is thus unclear whether LMO7 immunolabelling is correlated with the level of native LMO7 protein, splice variants or mutant protein. Although up-regulation of LMO7 has been observed by immunohistochemistry in various types of human cancers (13-15), the biological significance of these findings remains unknown. Our studies have demonstrated that overexpression of P100 LMO7, a splice variant induced by TGF- $\beta$, enhances the migration, proliferation and invasion of MDCK cells (unpublished data). Based on these oncogenic properties, up-regulation of LMO7 in various types of cancers may reflect a role in tumor progression.

In conclusion, down-regulation of LMO7 is related to the clinicopathological features of human lung adenocarcinoma and to the prognosis, but it remains unclear whether LMO7 may be a candidate for molecular-targeting therapy. Further studies are required to elucidate the role of LMO7 in the pathogenesis of human lung adenocarcinoma.

\section{References}

1. Jemal A, Siegel R, Ward E, Hao Y, Xu J and Thun MJ: Cancer Statistics, 2009. CA Cancer J Clin 59: 225-249, 2009.

2. Parkin DM: Global cancer statistics in the year 2000. Lancet Oncol 2: 533-543, 2001.

3. Naruke T, Tsuchiya R, Kondo H and Asamura H: Prognosis and survival after resection for bronchogenic carcinoma based on the 1997 TNM-staging classification: the Japanese experience. Ann Thorac Surg 71: 1759-1764, 2001.

4. Schiller JH, Harrington D, Belani CP, Langer C, Sandler A, Krook J, Zhu J and Johnson DH: Comparison of four chemotherapy regimens for advanced non-small cell lung cancer. N Engl J Med 346: 92-98, 2002.

5. Tanaka-Okamoto $\mathrm{M}$, Hori $\mathrm{K}$, Ishizaki $\mathrm{H}$, Hosoi $\mathrm{A}$, Itoh $\mathrm{Y}$, Wei M, Wanibuchi H, Mizoguchi A, Nakamura H and Miyoshi J: Increased susceptibility to spontaneous lung cancer in mice lacking LIM-domain only 7. Cancer Sci 100: 608-616, 2009.

6. Harris BZ and Lim WA: Mechanism and role of PDZ domains in signaling complex assembly. J Cell Sci 114: 3219-3231, 2001.

7. Kadrmas JL and Beckerle MC: The LIM domain: from the cytoskeleton to the nucleus. Nat Rev Mol Cell Biol 5: 920-931, 2004.

8. Holaska JM, Rais-Bahrami S and Wilson KL: Lmo7 is an emerinbinding protein that regulates the transcription of emerin and many other muscle-relevant genes. Hum Mol Genet 15: 3459-3472, 2006.

9. Ooshio T, Irie K, Morimoto K, Fukuhara A, Imai T and Takai Y: Involvement of LMO7 in the association of two cell-cell adhesion molecules, nectin and E-cadherin, through afadin and $\alpha$-actinin in epithelial cells. J Biol Chem 279: 365-373, 2004.

10. Nakamura H, Mukai M, Komatsu K, Tanaka-Okamoto M, Itoh Y, Ishizaki $\mathrm{H}$, Tatsuta $\mathrm{M}$, Inoue $\mathrm{M}$ and Miyoshi J: Transforming growth factor- $\beta 1$ induces LMO7 while enhancing the invasiveness of rat ascites hepatoma cells. Cancer Lett 220: 95-99, 2005.

11. Akedo A, Shinkai K, Mukai M, Mori Y, Tateishi R, Tanaka K, Yamamoto R and Morishita T: Interaction of rat ascites hepatoma cells with cultured mesothelial cell layers: a model for tumor invasion. Cancer Res 46: 2416-2422, 1986.

12. Mukai M, Shinkai K, Komatsu K and Akedo H: Potentiation of invasive capacity of rat ascites hepatoma cells by transforming growth factor- $\beta$. Jpn J Cancer Res 80: 107-110, 1989.

13. Kang S, Xu H, Duan X, Liu J-J, He Z, Yu F, Zhou S, Meng X-Q, Cao M and Kennedy G: PCD1, a novel gene containing PDZ and LIM domains, is overexpressed in several human cancers. Cancer Res 60: 5296-5302, 2000.

14. Furuya M, Tsuji N, Endoh T, Moriai R, Kobayashi D, Yagihashi A and Watanabe N: A novel gene containing PDZ and LIM domains, PCD1, is overexpressed in human colorectal cancer. Anticancer Res 22: 4183-4186, 2002.

15. Sasaki M, Tsuji N, Furuya M, Kondoh K, Kamagata C, Kobayashi D, Yagihashi A and Watanabe N: PCD1, a novel gene containing PDZ and LIM domains, is overexpressed in human breast cancer and linked to lymph node metastasis. Anticancer Res 23: 2717-2721, 2003.

16. Kainu T, Juo SH, Desper R, et al: Somatic deletions in hereditary breast cancers implicate $13 \mathrm{q} 21$ as a putative novel breast cancer susceptibility locus. Proc Natl Acad Sci USA 97: 9603-9608, 2000.

17. Rozenblum E, Vahteristo P, Sandberg T, et al: A genomic map of a $6-\mathrm{Mb}$ region at 13q21-q22 implicated in cancer development: identification and characterization of candidate genes. Human Genet 110: 111-121, 2002.

18. Thompson D, Szabo CI, Mangion J, et al: Evaluation of linkage of breast cancer to the putative BRCA3 locus on chromosome $13 \mathrm{q} 21$ in 128 multiple case families from the breast cancer linkage consortium. Proc Natl Acad Sci USA 99: 827-831, 2002.

19. Travis WD, Colby TV, Corrin B, Shimosato Y and Brambilla E: Histological typing of lung and pleural tumors. In: World Health Organization International Histological Classification of Tumors (3rd edition). Springer, Berlin, 1999.

20. Sobin L and Wittekind CH: TNM Classification of Malignant Tumours (6th edition). Wiley-Liss, New York, 2002.

21. Kaplan EL and Meier P: Nonparametric estimation for incomplete observations. J Am Stat Assoc 53: 457-481, 1958.

22. Peto R, Pike MC, Armitage P, Breslow NE, Cox DR, Howard SV, Mantel N, McPherson K, Peto J and Smith PG: Design and analysis of randomized clinical trials requiring prolonged observation of each patient. II. Analysis and examples. Br J Cancer 35: 1-39, 1977. 